\title{
2248'54' - Sob a Luz do Sol: Apropriação do Trajeto Solar para Explorar a Singularidade de Experiências
}

\author{
22 ${ }^{\circ} 8^{\prime} 54 "$ - Under the Sunlight: Appropriation of the Solar Path as way to Explore the \\ Singularity of Experiences
}

\author{
Juliana Croffi \\ Universidade Estadual de Campinas, Brasil \\ jucroffi@hotmail.com \\ Henrique Lattes \\ Universidade Estadual de Campinas, Brasil \\ hlattes@gmail.com

\section{Márcio Guirado} \\ Universidade Estadual de Campinas, Brasil \\ marcio@grid-arquitetura.com.br
}

\author{
Barbara Maia \\ Universidade Estadual de Campinas, Brasil \\ barbarahmaia@gmail.com \\ Milene Mamede \\ Universidade Estadual de Campinas, Brasil \\ Milene@mamede.com.br
}

\begin{abstract}
22\%48'54" - Under the Sunlight is an architectural installation, an experimentation product of an academic research using parametric algorithms, computational design and digital fabrication in it's conception and execution. It's title and form are answers to the sun path and it's incidence in a specific place - the Exploratory Science Museum at Unicamp (State University of Campinas). The installation is a honeycomb structure of twelve unique modules digitally fabricated from MPU, a composed board of polyethylene and aluminium, oriented with the different sun positions during the day in Campinas. Five of those twelve modules are covered in panels with different openings, which provide different shading patterns according with the evolution of the day.
\end{abstract}

Keywords: Simulação; Insolação; Fabricação Digital; Customização.

\section{Introdução}

Com os avanços tecnológicos computacionais de simulação e fabricação a qualidade do projeto arquitetônico avança para atingir patamares de precisão e eficiência que até então só eram possíveis em outras indústrias, como automobilística, naval, aeroespacial.

Nos últimos anos vimos crescer o número de máquinas de corte a laser, router $C N C$, impressoras $3 D$ entre outras tecnologias que permitem além da prototipação rápida, a produção de componentes construtivos que podem ser fabricados diretamente por essas máquinas e utilizados na arquitetura.

O computador transformou não só a maneira que projetamos arquitetura e objetos de todas as escalas, mas a maneira como as fabricamos, redefinindo a relação entre pensar e fazer. Essa redefinição é muitas vezes apresentada como uma saída radical da modernidade industrial como a conhecemos. Em termos de fabricação, agora parece possível conciliar singularidade e repetição, personalização avançada e métodos genéricos de produção. O objeto exclusivo e a série já não parecem mais irreconciliáveis. (Picon A., 2014).

Neste artigo procuramos discutir o papel do arquiteto enquanto mediador entre essas tecnologias e necessidades envolvidas no projeto, através da habilidade de gerar e analisar as informações digitais do design e então usá-las diretamente na manufatura, redefinindo a relação entre concepção e produção, descrito por Kolarevic como Digital Continuum - um continuum informacional do design à construção. (Kolarevic, 2003).

Nesse experimento propusemos avaliar essa mediação e essa nova relação entre pensar em fazer, considerando no exercício o nível de controle permitido através de plugins de simulação de insolação e a precisão na fabricação CAM a través do uso de router $C N C$ de três eixos.

2248'54" - Sob a luz do Sol é uma instalação arquitetônica, resultado de uma experimentação desenvolvida em um exercício acadêmico que utiliza algoritmos paramétricos, design computacional e fabricação digital tanto em sua concepção quanto em sua execução.

\section{Metodologia de projeto (CAD)}

\section{Premissas}

O experimento apresentado tratou-se de um exercício acadêmico realizado na Universidade Estadual de Campinas (UNICAMP). A proposta do exercício consistia na concepção e construção de uma instalação temporária para a área externa do Museu Exploratório da Ciência, situada dentro do campus da universidade. Para isso era necessária a utilização dos métodos de desenho por algoritmos paramétricos, 
prototipagem e fabricação digital, que faziam parte do objetivo principal do trabalho. A instalação deveria ser fabricada digitalmente usinando 5 placas de MPU em uma router CNC. Após a usinagem, a montagem da estrutura poderia contar com alguns acessórios de fixação das placas para a instalação final no espaço externo ao Museu.

Esta disciplina aconteceu na Unicamp entre setembro e novembro de 2016, desde a concepção até a instalação final.

O MPU (Figura 1) é um produto fabricado pela empresa Multivac Poliuretanos. É composto por placas de espuma rígida de poliuretano revestidas de alumínio nas duas principais faces, com dimensões em torno de $2200 \times 1200 \times$ $20 \mathrm{~mm}$. É um material comumente utilizado para dutos de ar condicionado por ser leve, isolante, de fácil usinagem e de certa rigidez. Por também possuir uma considerável resistência a intempéries, se torna ainda mais adequado ao nosso uso.

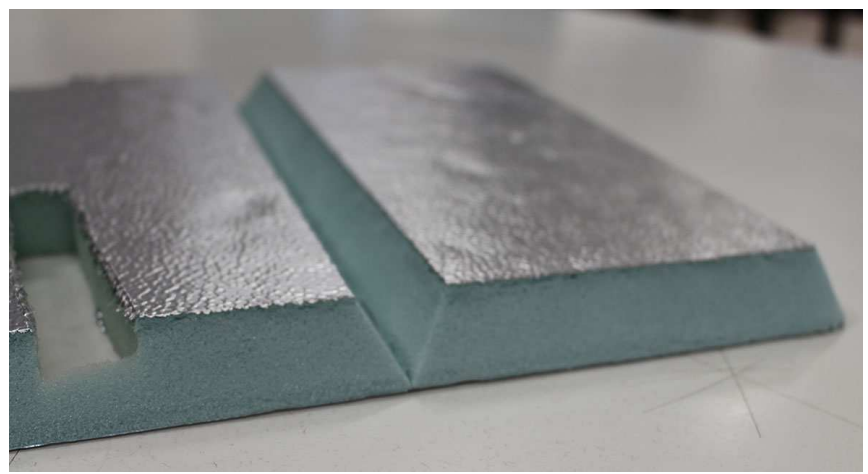

Figura 1: Detalhe de uma placa de MPU usinada.

Utilizamos a router CNC (Figura 2) do LAPAC (Laboratório de Automação e Prototipagem para Arquitetura e Construção) da própria Unicamp, fabricada pela Vitor Ciola, modelo Scriba $1020 \mathrm{H}$ com 3 eixos, volume de corte de $2000 \times 1000 \times 300 \mathrm{~mm}$ e mesa com sistema à vácuo. A fresa disponível tinha diâmetro da haste de $6 \mathrm{~mm}$, flauta dupla e cabeça plana.

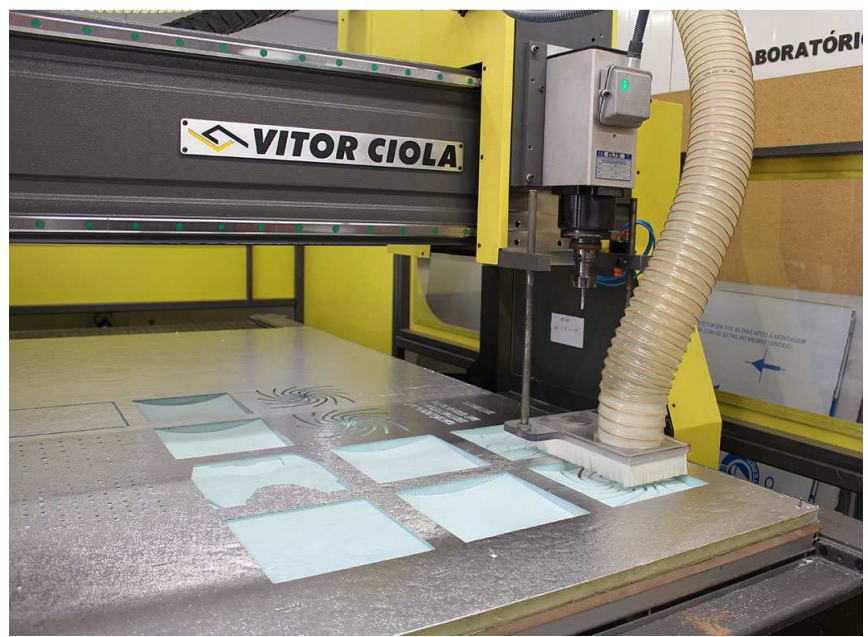

Figura 2: Router CNC Vitor Ciola.
Com estas premissas, decidimos desenvolver um projeto que explorasse a precisão da fabricação digital e que encontraria limitações em sua construção pelos métodos convencionais de fabricação. Como há no museu uma exposição permanente sobre a luz e seus aspectos físicos, buscamos explorar também a relação entre o artefato e a luz solar. Além disso, procuramos explanar a liberdade de criação que a tecnologia oferece ao designer, uma vez que o resultado final executado por máquinas de fabricação por controle numérico computadorizado corresponde fielmente às complexas formas projetadas. Criamos assim uma estrutura suspensa por cabos dividida em módulos direcionados para a posição do sol em diferentes horas durante os últimos dias de novembro no céu de Campinas.

\section{Projeto (CAD)}

Através do software Rhinoceros, dos plug-ins Grasshopper e LadyBug e do arquivo EPW (Energyplus Weather Data) para o local do Museu (2248'54"), obtivemos informações precisas sobre o posicionamento do sol. Com os resultados das análises do plugin Ladybug, determinamos os vetores formados entre o centro do artefato e a posição do sol nas diferentes horas do dia (Figura 3). Então criamos um algoritmo (Figura 4) que desenvolve uma espécie de colmeia curvada, onde cada alvéolo é precisamente orientado pelos vetores solares.

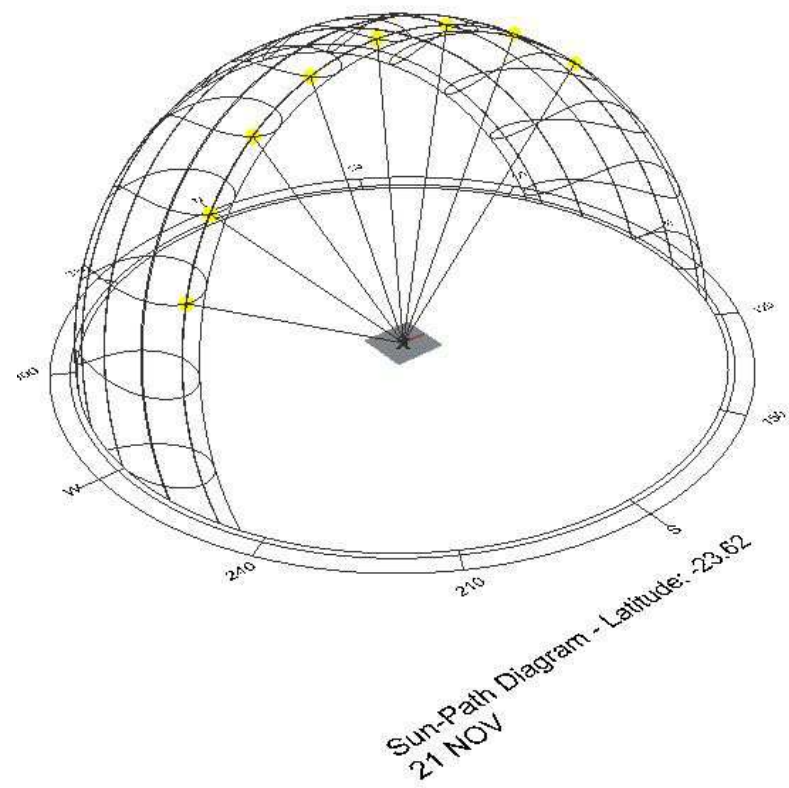

Figura 3: Vetores entre o centro da instalação e a posição do sol durante as horas do dia. 


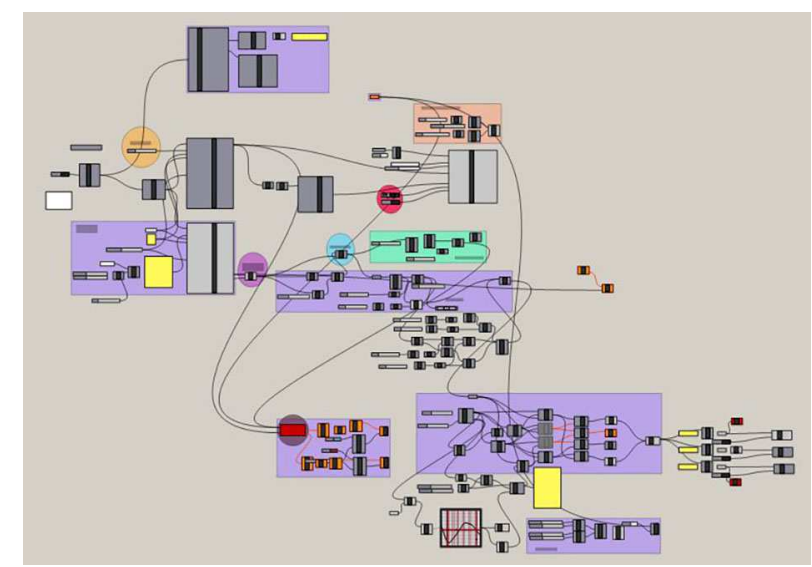

Figura 4: Algoritmo do Grasshopper.

Como as placas de MPU apresentam bastante resistência a esforços paralelos às maiores faces do painel e pouca resistência a esforços perpendiculares às maiores faces, optamos pela forma de colmeia curvada (Figura 5), pois ela se subdivide em módulos alveolares (Figura 6) em que as dimensões da maior face não ultrapassam 30 vezes a espessura da placa, agregando maior resistência à instalação. O formato côncavo respeitou o caminho do sol, orientando corretamente cada alvéolo e permitindo maior estabilidade ao conjunto.

A estrutura inteira é composta por 12 alvéolos um diferente do outro. Cada alvéolo composto por 6 faces, uma diferente da outra e cada ângulo interno diferente do outro.

Cinco dos alvéolos foram fechados com tampas de MPU projetadas com diferentes desenhos a serem gravados nessas tampas, fazendo com que as diferentes sombras projetadas por elas no piso demarcassem a evolução do sol durante o dia.

A plasticidade formal responde às premissas de acompanhar o caminho do sol e ser autoportante ao mesmo tempo usando o material MPU. Além disso, exige uma extrema precisão da fabricação e se torna bastante complexa para se fabricar com recursos tradicionais por sua falta de unidade dimensional. Assim, atende também ao objetivo proposto para a fabricação digital deste exercício.

A etapa final do projeto (CAD) foi planificar e identificar os 12 alvéolos e as 5 tampas. Assim podemos começar a planejar o procedimento de fabricação (CAM).

\section{Metodologia de fabricação (CAM) Processo CAM}

Para desenvolver o procedimento de fabricação, foi utilizado o plugin RhinoCAM, que também é um plugin do Rhinoceros, o que facilita bastante a visualização e interação entre as etapas de projeto e os procedimentos de fabricação.

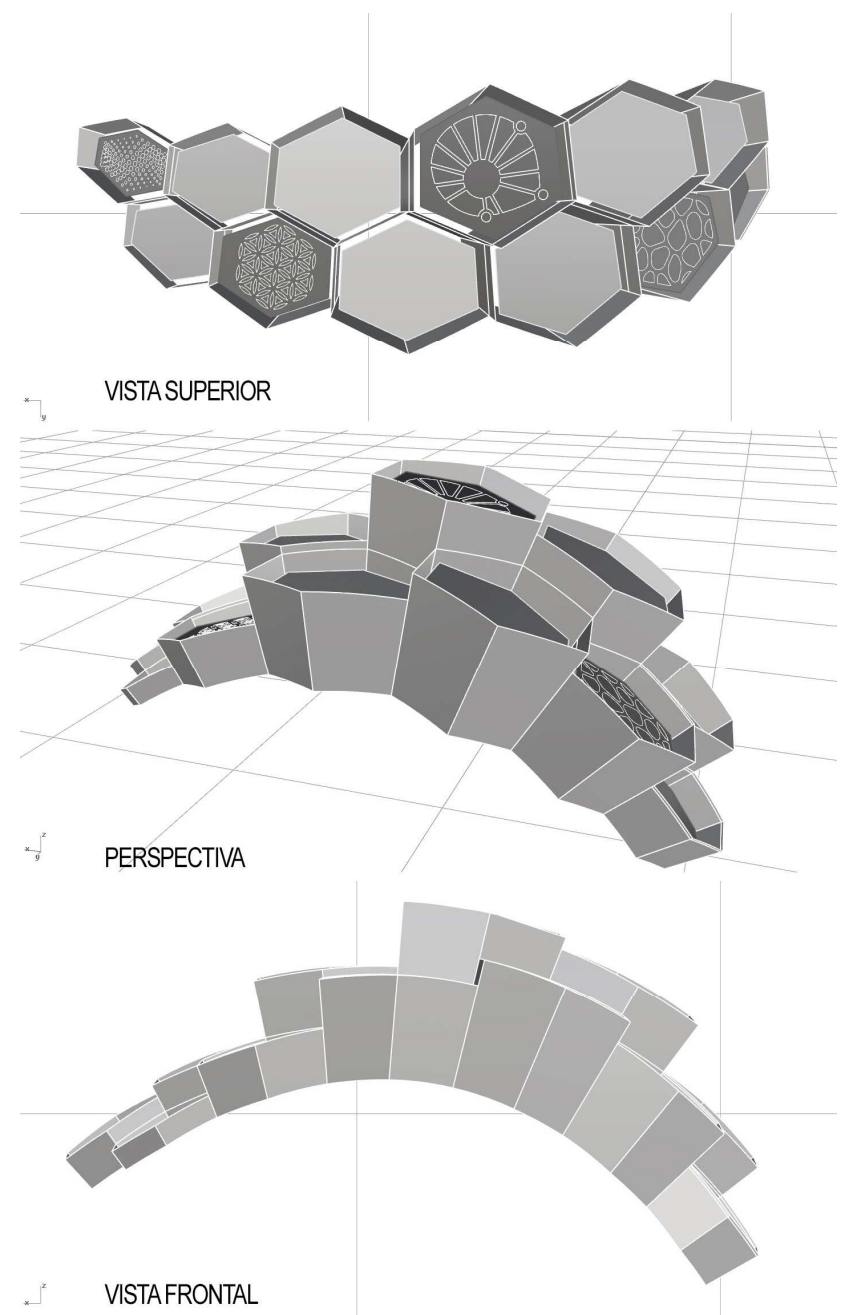

Figura 5: Estrutura em forma de colmeia curvada.

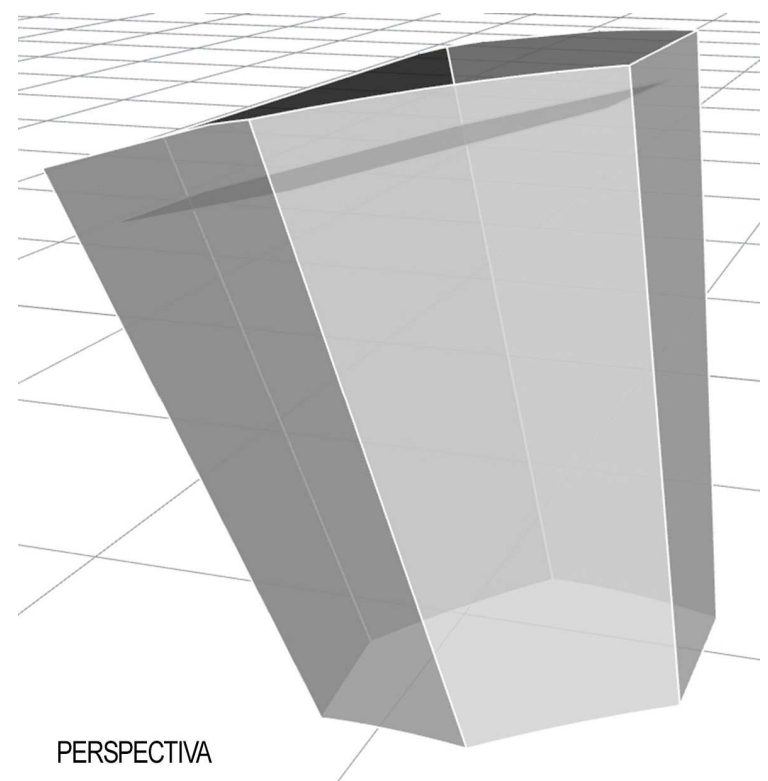

Figura 6: Detalhe do maior alvéolo, formato de cunha e secção hexagonal irregular. 
Nessa etapa também foram feitos alguns protótipos para testar as soluções propostas. O resultado dos testes realimentou os procedimentos de corte e algumas vezes 0 próprio projeto para obtermos o resultado desejado.

No software RhinoCAM definimos modelos de fresa, sentido e velocidade de rotação, velocidade de corte, tipos de movimento de corte, paginação das figuras a serem cortadas dentro da placa da matéria prima, entre outras configurações.

Para usinar os ângulos específicos ilustrados na Figura 8, foi utilizado o procedimento chamado parallel finishing, em que se delimita uma área sobre a região em que se quer a usinagem com interpolação de 2 ou 3 eixos. O RhinoCAM então lê a volumetria abaixo da projeção desta área delimitada e calcula automaticamente o caminho da fresa para se obter esta superfície (Figura 9). O software respeita inclusive o diâmetro de $6 \mathrm{~mm}$ da fresa e se aproxima do limite para que a superfície oposta não seja atingida. Para extrair o material que a fresa não consegue cortar, foi utilizado o estilete usando a face já usinada como guia, retirando-se o excesso de material (retirada manual de material: Figura 9).

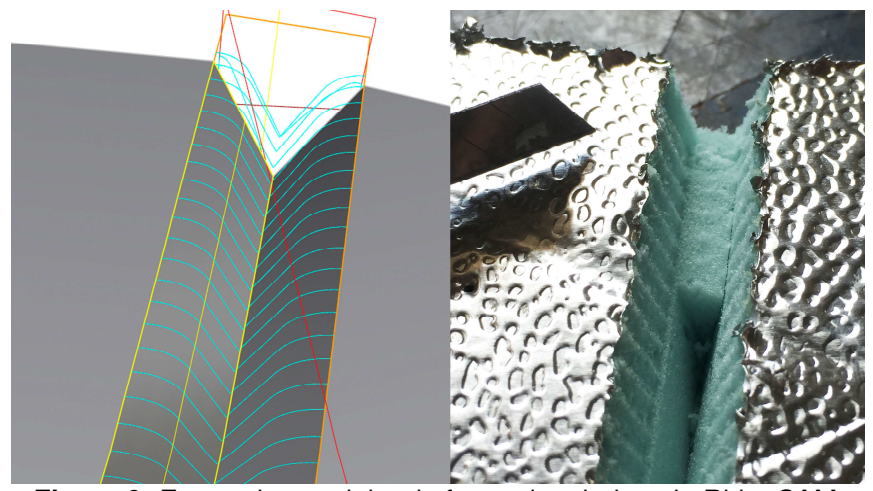

Figura 9: Esquerda: caminho da fresa planejado pelo RhinoCAM. Direita: resultado da usinagem e estilete que corta o excesso onde a fresa não pôde chegar.

Destes procedimentos retira-se um arquivo de texto que contém todas as coordenadas $x, y, z$ em que a fresa deve estar conforme variação do tempo. Este arquivo é enviado para a router e fica disponível para que se inicie a usinagem.

\section{Preparo antes do corte das peças}

No preparo da máquina antes do corte foram adotados alguns procedimentos para economizar tempo e material. Zerando a máquina, foi marcado um ponto de referência na placa de MPU para permitir que ela pudesse ser reposicionada e um novo corte fosse orientado corretamente.

Um grande problema enfrentado foi a planicidade da matéria prima. Sem uma análise precisa, as placas parecem planas. Em procedimentos onde ângulos serão usinados e a precisão exigida é alta como neste caso, $1 \mathrm{~mm}$ de relevo na superfície de uma placa de 2200 x 1200 milímetros precisa ser considerado. Em um dos primeiros alvéolos cortados percebeu-se como isso influencia o resultado. A chapa estava empenada para cima da mesa no trecho onde a figura foi cortada, assim a fresa usinava considerando a posição correta e o vinco ficou mais profundo do que planejado (Figura 10). Com esta folga nos ângulos internos, o alvéolo montado não mantinha sua forma projetada e precisou ser descartado.

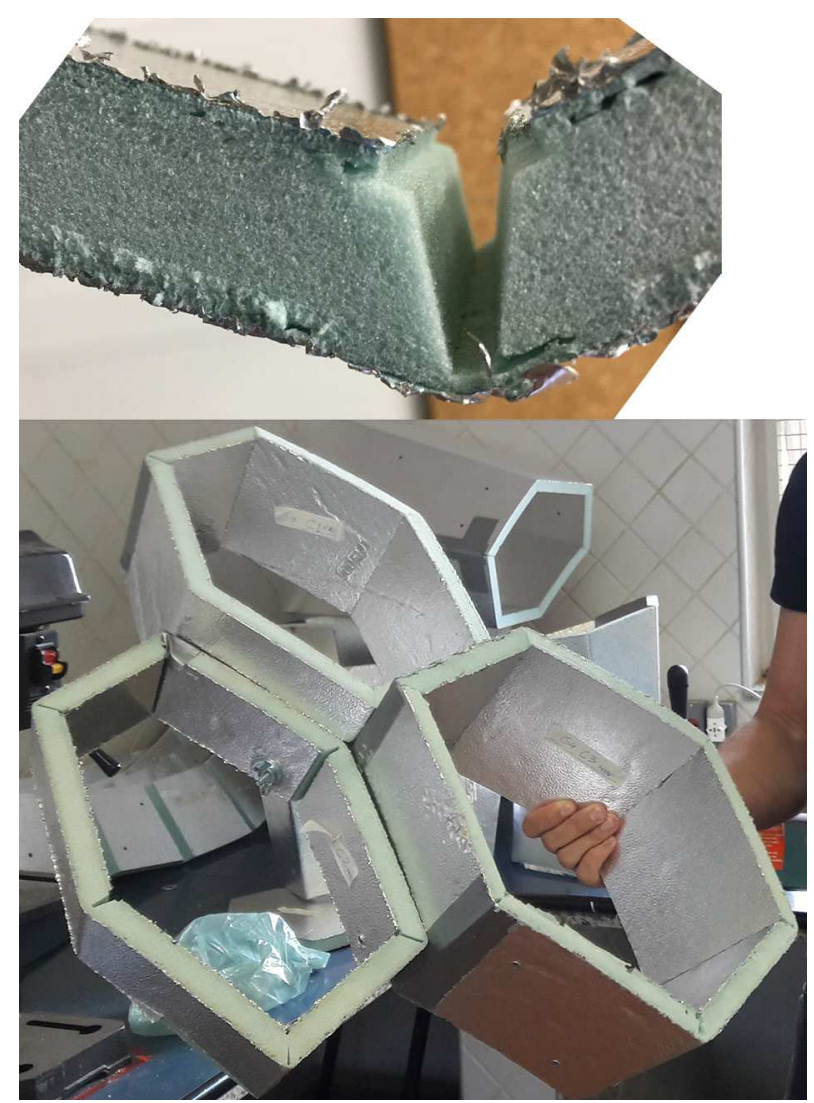

Figura 10: Acima: ângulo usinado abaixo do planejado.

Abaixo: o alvéolo a esquerda com folga nos ângulos internos precisou ser descartado.

Neste caso, foi criado um procedimento de verificação de planicidade da placa: ainda no RhinoCAM foram desenhados alguns quadrados de apenas $15 \times 15 \mathrm{~mm}$ espalhados ao redor da figura a ser cortada, com procedimento de corte para eles. Os quadrados ficavam posicionados $0,10 \mathrm{~mm}$ acima da placa de MPU, então se a placa estivesse alinhada a fresa deveria passar muito próximo do material sem fazer nenhum corte. Caso cortasse em algum ponto, o procedimento era reavaliado e alinhado pelo ponto mais alto da figura a ser usinada (Figura 11). 


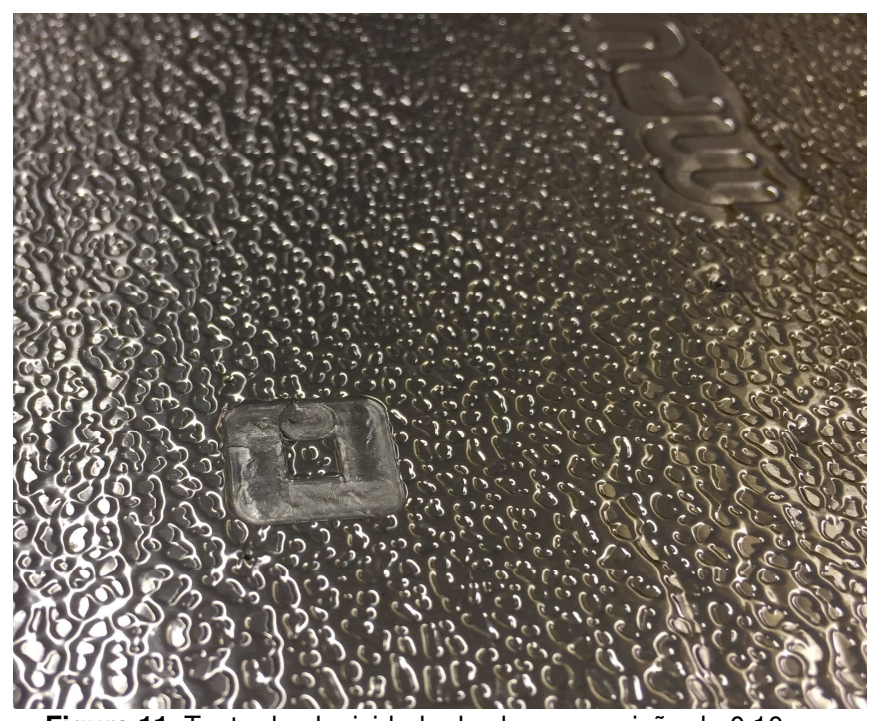

Figura 11: Teste de planicidade da chapa, precisão de $0,10 \mathrm{~mm}$.

\section{Fabricação}

Os alvéolos foram fechados manualmente e a única aresta aberta era presa com fita adesiva e cola (Figura 12). Cada alvéolo foi projetado com furos coincidentes entre as faces que se encontram, para que fossem presos uns aos outros com parafusos.

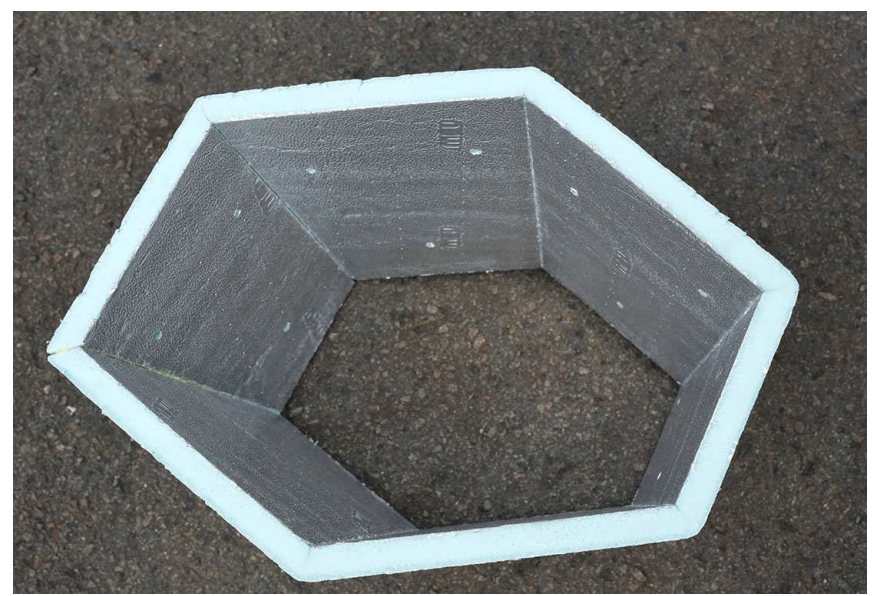

Figura 12: Maior alvéolo montado, mesma peça da figura 6.

\section{Instalação}

Através de 3 cabos de aço e tensores para ajuste fino, a estrutura montada foi suspensa e posicionada no local exato (Figura 13).

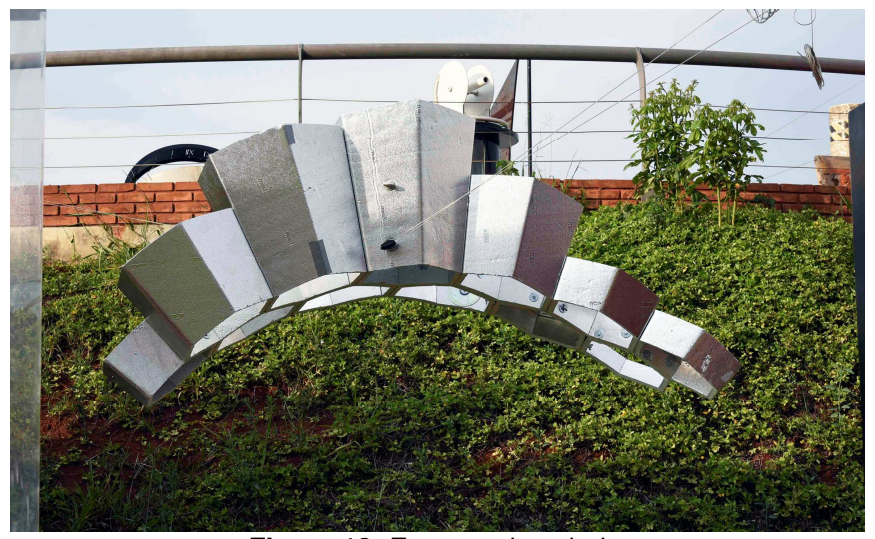

Figura 13: Estrutura instalada.

Como planejado, as tampas perfuradas com diferentes imagens projetaram sua sombra no piso conforme a hora do dia (Figura 14).

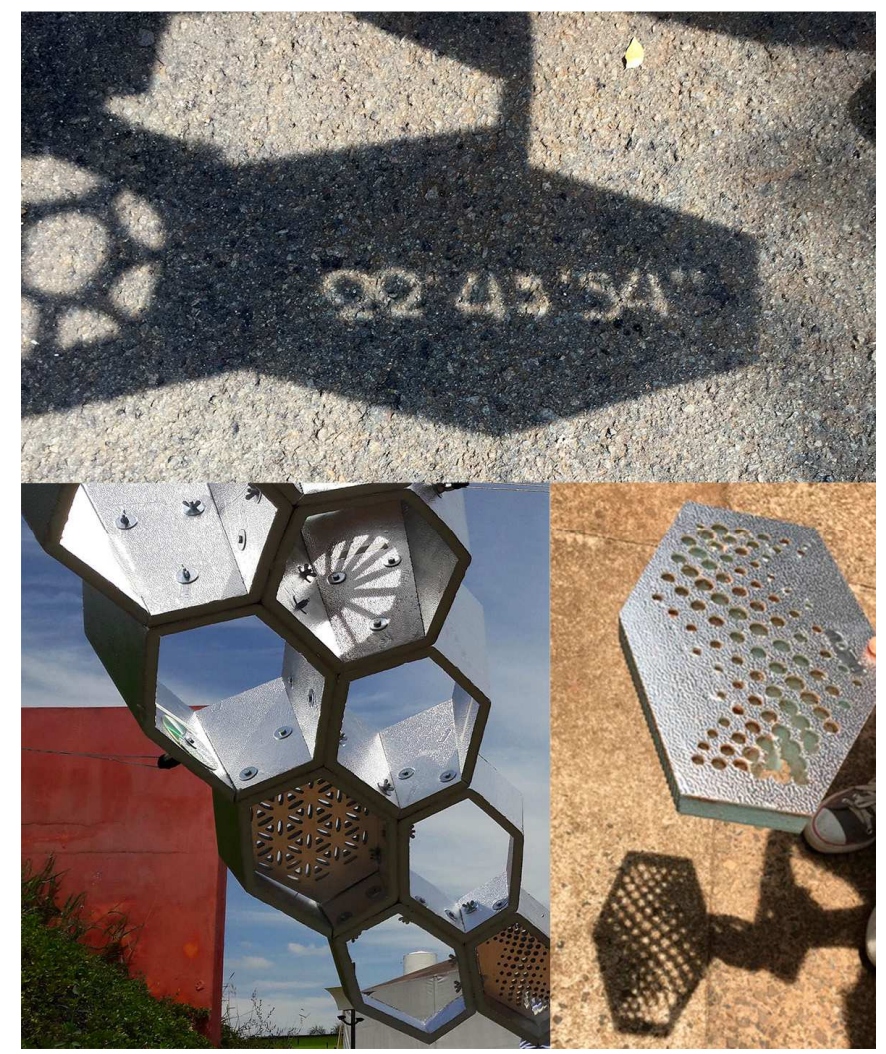

Figura 14: Acima: no meio da tarde, a latitude do Museu aparece projetada no piso. Abaixo esquerda: As outras imagens não são projetadas no piso por conta do posicionamento do sol. Abaixo direita: Tampa do sol do começo da manhã, fora da estrutura, mostra seu padrão de projeção no piso. 


\section{Resultados}

O resultado de fabricação alcançado foi extremamente fiel ao modelo tridimensional projetado. $\mathrm{O}$ uso de algoritmos generativos para atender ao conceito inicial do projeto foi indispensável. O processo também garantiu boa rigidez da estrutura considerando o material em que foi fabricada.

Durante a instalação, vivenciamos outra característica destas tecnologias. A estrutura sofreu um acidente e no impacto de uma queda danificou um dos alvéolos no dia da apresentação. Foi preciso apenas voltar ao laboratório, posicionar a placa de MPU na mesa e iniciar o procedimento de corte já pronto para aquele alvéolo. Alguns minutos depois, um novo estava instalado na estrutura que voltou a sua integridade.

Entretanto a performance em relação ao movimento do sol foi prejudicada devido à imprecisão da instalação através dos cabos de aço e dos pontos onde foram presos, o que dependia diretamente de habilidades pessoais dos envolvidos nessa etapa da execução.

\section{Conclusão}

O processo de desenho paramétrico e fabricação digital pode empoderar o arquiteto. Na etapa da execução muitas vezes o projeto sofre alterações devido a restrição de custos, tempo e em função das limitações da fabricação tradicional comprometendo a eficiência e a estética do objeto proposto. Aplicar estas novas tecnologias ainda durante o projeto permite controle a maior de todas as etapas posteriores, como a garantia de maior previsibilidade de tempo e custos de fabricação minimizando qualquer adequação futura.

Permite também que ainda na fase de projeto a eficiência da construção seja testada e otimizada atendendo às condições a que ela estará futuramente exposta. Todas estas características conferem ao arquiteto grande liberdade plástica formal abrindo novas fronteiras para 0 desenvolvimento da arquitetura.

O desenho paramétrico e a fabricação digital poderão agregar às novas construções algo além do que experimentamos nesse exercício. Seja por desgaste de uso, seja por uma reforma, seja porque o usuário se transformou, um trecho de uma residência poderá ser fabricado para substituir ou complementar o antigo, mesmo depois de anos de uso após sua conclusão.

Estas peças poderão ser fabricadas em impressoras $3 \mathrm{~d}$ ou router $C N C$ mais próximas do local de instalação, estimulando a concorrência entre fabricantes e diminuindo o custo e impacto do transporte. Poderão permitir pequenas intervenções, constante manutenção, aumentando significativamente a vida útil das construções. Poderá ser possível conseguir adaptabilidade e resiliência, sem a obrigatoriedade da padronização industrial, tornando possível a customização em massa.

"In the future, technological innovation will also lead to a supply side miracle, with long term gains in efficiency and productivity. Transportation and communication costs will drop, logistics and global supply chains will become more effective, and the cost of trade will diminish, all of which will open new markets and drive economic growth." (Schwab, K., 2015)

Porém o processo de projeto através de algoritmos requer domínio de linguagem computacional a qual muitos arquitetos não estão habituados, tornando o controle do resultado muito relativo e dependente do conhecimento que o profissional possui com relação à esse método, podendo gerar resultados inesperados ou incompletos.

Por isso o conhecimento e o envolvimento do arquiteto no processo de fabricação podem ser definitivos para o sucesso do resultado final. "We believe that architects must acquire a set of skills which includes programming and fabrication technologies. This knowledge is important to produce coherent results, and to avoid problems in the design fabrication." (Sedrez, 2017; Celani, 2017). Sendo assim, se faz necessária a introdução dos métodos de design computacionais e digitais no processo de aprendizado dos futuros profissionais, a fim de que se domine tais ferramentas para que se possa aplicá-las com eficiência ao fluxo do Digital Continuum.

\section{Agradecimentos}

Unicamp e LAPAC.

\section{Referencias}

CANEPARO, L. (2014) Digital Fabrication in Architecture, Engineering and Construction; Foreword by Antoine Picon.

KOLAREVIC, B. (2003) Architecture in digital age; Design and manufacturing. Performative Architecture: Beyond Instrumentality (2005) Why We Need Architecture of Tolerance (2014).

SEDREZ, M., CELANI, G. (2017) The new ornament in architecture. Arquitextos. Retirado de http://www.vitruvius.com.br/revistas/ read/arquitextos/17.204/6549.

SCHWAB, K. (2015) The Fourth Industrial Revolution - What It Means and How to Respond 